\title{
Multi-Hazard Evaluation Using Cluster Analysis-For Designated Evacuation Centers of Yokohama
}

\author{
Tsutomu Ochiai, Takahisa Enomoto \\ Kanagawa University, Kanagawa, Japan \\ Email: ochiai@kanagawa-u.ac.jp
}

How to cite this paper: Ochiai, T. and Enomoto, T. (2021) Multi-Hazard Evaluation Using Cluster Analysis-For Designated Evacuation Centers of Yokohama. Journal of Geographic Information System, 13, 243-259.

https://doi.org/10.4236/jgis.2021.132013

Received: February 22, 2021

Accepted: April 22, 2021

Published: April 25, 2021

Copyright $\odot 2021$ by author(s) and Scientific Research Publishing Inc. This work is licensed under the Creative Commons Attribution International License (CC BY 4.0).

http://creativecommons.org/licenses/by/4.0/

\begin{abstract}
Hazard maps are usually prepared for each disaster, including seismic hazard maps, flood hazard maps, and landslide hazard maps. However, when the general public attempts to check their own disaster risk, most are likely not aware of the specific types of disaster. So, first of all, we need to know what kinds of hazards are important. However, the information that integrates multiple hazards is not well maintained, and there are few such studies. On the other hand, in Japan, a lot of hazard information is being released on the Internet. So, we summarized and assessed hazard data that can be accessed online regarding shelters (where evacuees live during disasters) and their catchments (areas assigned to each shelter) in Yokohama City, Kanagawa Prefecture. Based on the results, we investigated whether a grouping by cluster analysis would allow for multi-hazard assessment. We used four natural disasters (seismic, flood, tsunami, sediment disaster) and six parameters of other population and senior population. However, since the characteristics of the population and the senior population were almost the same, only population data was used in the final examination. From the cluster analysis, it was found that it is appropriate to group the designated evacuation centers in Yokohama City into six groups. In addition, each of the six groups was found to have explainable characteristics, confirming the effectiveness of multi-hazard creation using cluster analysis. For example, we divided, all hazards are low, both flood and Seismic hazards are high, sediment hazards are high, etc. In many Japanese cities, disaster prevention measures have been constructed in consideration of ground hazards, mainly for earthquake disasters. In this paper, we confirmed the consistency between the evaluation results of the multi-hazard evaluated here and the existing ground hazard map and examined the usefulness of the designated evacuation center. Finally, the validity was confirmed by comparing this result with the ground hazard based on the ac-
\end{abstract}


tual measurement by the past research. In places where the seismic hazard is large, the two are consistent with the fact that the easiness of shaking by actual measurement is also large.

\section{Keywords}

Multi Hazard, Cluster Analysis, Open Data, Designated Evacuation Center, GIS

\section{Introduction}

Since ancient times, Japan has suffered many earthquake disasters and many casualties have occurred. Therefore, evacuation center in the event of a disaster is regarded as important, and designated evacuation centers are set for each city. However, due to global warming, meteorological disasters have become more frequent in recent years, and heavy rains, typhoons and associated sediment-related disasters have also occurred frequently. In addition, since the 2011 Great East Japan Earthquake, tsunami disasters caused by huge subduction-zone earthquakes have become a concern, and it is necessary to consider the effectiveness of existing designated evacuation centers for various disasters.

Japan is a country with one of the highest risks for natural disasters such as seismic and floods. Therefore, many surveys and studies about disaster have been conducted and a large volume of documents has been accumulated regarding disaster countermeasures. To enable municipalities to respond to multiple disasters, Nakabayashi and Otagiri [1] defined complex disasters and extensive and massive disasters and discussed the current situations and challenges. And Okano [2] discusses the need for consideration assuming a combination of multiple disasters, although the probability is low. The Ministry of Land, Infrastructure, Transport and Tourism prepared an "overlay hazard map" where disaster risk information can be overlaid under the Hazard Map Portal Site [3], making efforts toward the clear assessment of hazard. Other examples of previous research in Japan are given below [1]-[8]. There are research focusing on evacuation behavior due to complex disasters by Takada et al. [4] [5], research on damage reduction measures focusing on seismic and floods caused by Itagaki et al. [6], research on storm surge inundation prediction when a typhoon hits after a seismic by Kawasaki et al. [7]. And Tamura et al. [8] proposes a method for assessing multi-hazard risk by incorporating probabilistic ideas and integrating risk curves for individual disasters. This paper also introduces the entry into force of the Disaster Mitigation Act (2000) [9] and FEMA's Multi-hazard Information Platform [10] as US efforts. In addition, hazard maps have been extensively studied, for example, there are Szu-Hsien Peng et al. [11] as an example of study on floods and debris flows in Taiwan, and an example of study on land movement in Algeria by Amar Guettouche [12]. Studies that classify regional characteristics from cluster analysis include Sangeeta [13] and R. Ley [14]. 
However, there are not many studies that consider multiple hazards.

When non-experts, such as municipal staff and the general public, examine disaster response, we can assume that the first reference they would turn to would be the hazard map prepared by the federal and local governments. Hazard maps are usually prepared for each disaster, including seismic hazard maps, flood hazard maps, and landslide hazard maps. However, when the general public attempts to check their own disaster risk, most are likely not aware of the specific types of disaster. In other words, they want to know their overall risk of disaster. In such a case, information to determine the characteristics of one's own area in regard to all disasters becomes of primary importance. However, it is difficult for the general public to make a comprehensive assessment using multiple hazard maps or to judge which hazard maps should be prioritized and which ones are unnecessary [15] [16]. When municipality staff examine evacuation center facilities or explain disaster countermeasures for residents, they need to know all types of hazard information.

Meanwhile, much of the hazard information in Japan is stored into databases, and the system is set up so that data can be easily accessed online [17]. Experts can weed through the data and select the necessary information, which makes such data extremely useful. However, this data is not utilized by general public [18].

Thus, in the present study, we summarized and assessed hazard data that can be accessed online regarding evacuation center (where evacuees live during disasters) and their catchments (areas assigned to each evacuation center) in Yokohama City, Kanagawa Prefecture. Based on the results, we investigated whether a grouping by cluster analysis would allow for multi-hazard assessment. In addition, the authors are creating a ground hazard map using actual measurement records using constant microtremors in Yokohama City, which is the subject of research [19] [20]. The validity was confirmed by comparing this result with the ground hazard based on the actual measurement.

The structure from the next section onward is shown. The $2^{\text {nd }}$ section is the characteristics of the target area, Yokohama City. It mainly summarizes topographical features. The $3^{\text {rd }}$ section is the data and research methods used. We have summarized the sources and characteristics of five types of data and the policy of cluster analysis. The $4^{\text {th }}$ section is the results and discussion. We have summarized the results of the cluster analysis and the comparison with the previous studies. And the $5^{\text {th }}$ section is a conclusion.

\section{Characteristics of the Target Area, Yokohama City}

Yokohama City is located on the east side of Kanagawa Prefecture, and is considered as one of the central cities of the metropolitan area with the international port of Yokohama as its base. As of 2019, Yokohama City was a major city with a population exceeding 3.7 million people, only second to the special wards of Tokyo [21] [22]. 
Figure 1 shows Location of Yokohama City, Figure 2 shows the microtopography of Yokohama City [23], and Figure 3 shows the elevation distribution [24]. The topography of Yokohama can be roughly divided into hills, plateaus,

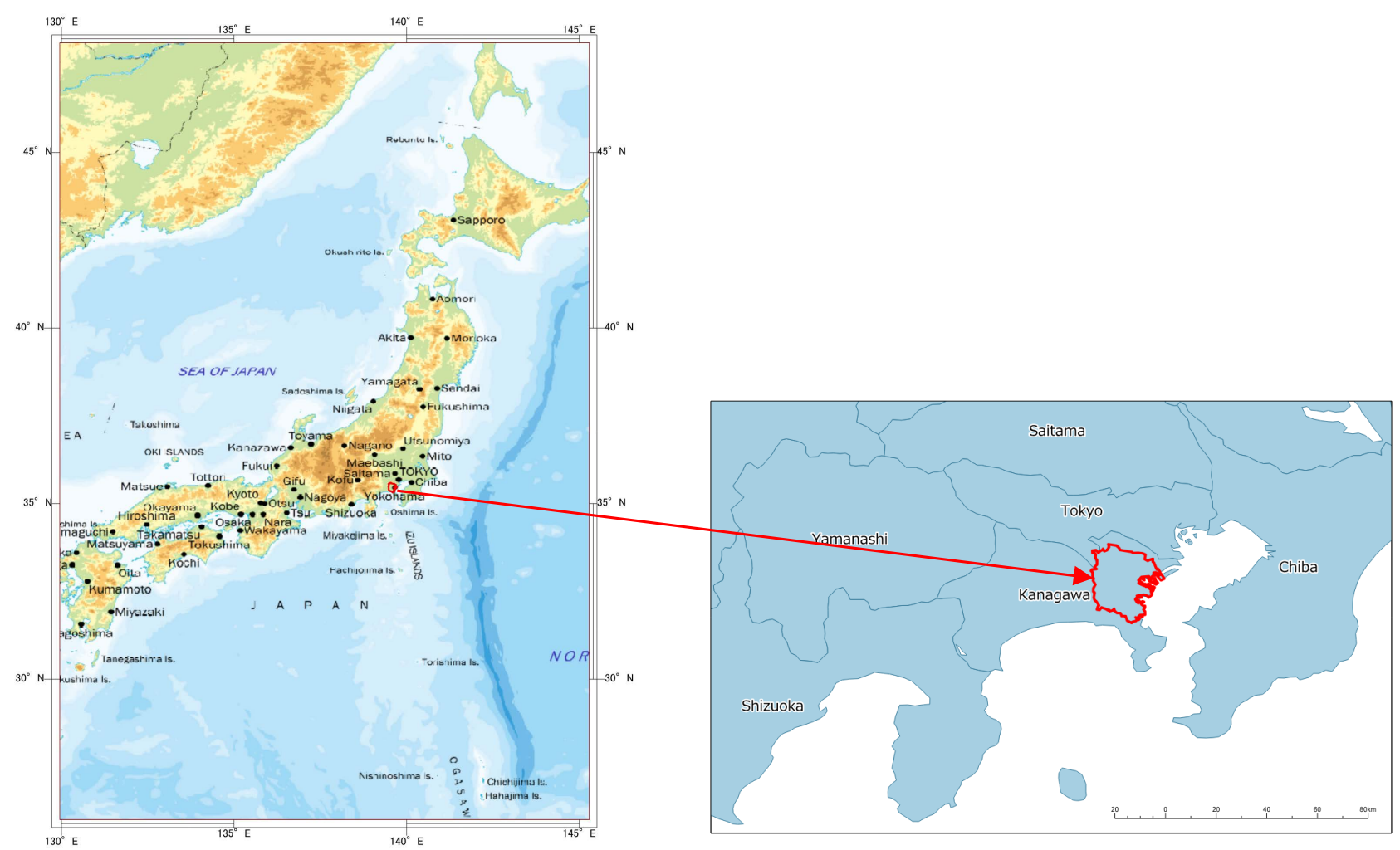

Figure 1. Location of Yokohama City.

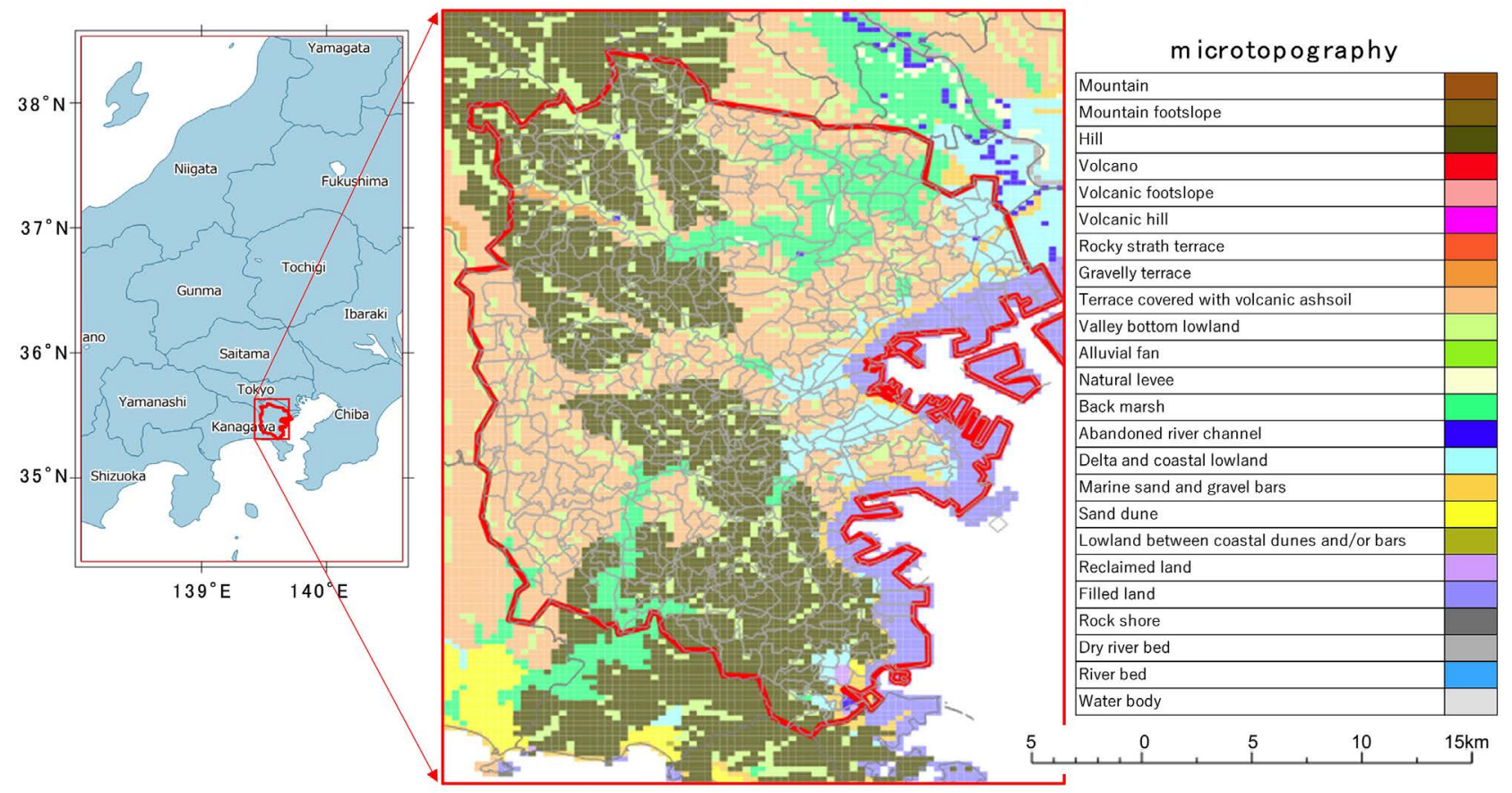

Figure 2. Microtopography of Yokohama [23]. 


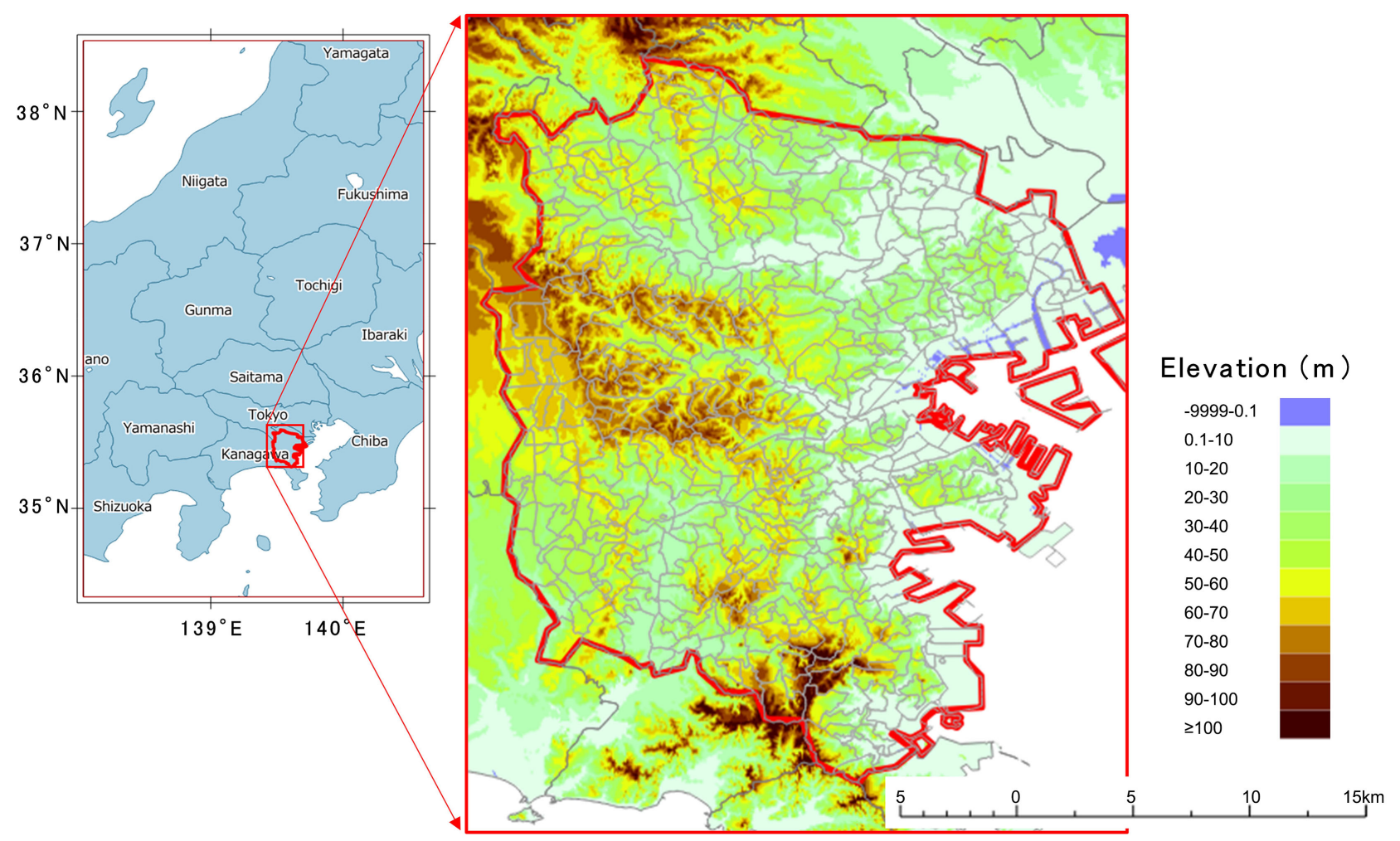

Figure 3. Elevation distribution of Yokohama [24].

terraces, lowlands, and landfills. Hills and plateaus are about $70 \%$ of the City, while the other $30 \%$ are alluvial plains along rivers and landfills along the ocean. Hills spread in the southeastern area, where relatively steep slopes are not uncommon.

Yokohama City was hit hard by the Great Kanto Earthquake in 1923, when over 20,000 died and 60,000 buildings were destroyed. This was followed by other large earthquakes with seismic intensity of approximately 5 , such as the 1924 Tanzawa Earthquake and the 1930 North Izu Earthquake, which fortunately caused no major damage. However, during the Great East Japan Earthquake of 2011, Yokohama City experienced significant shaking, with a maximum seismic intensity of $5+$, accompanied by major damage centered around the areas of softer ground. Landslides and floods caused by typhoons accompanied by torrential rain are relatively common. For example, the Yokohama Local Meteorological Office has summarized 80 major weather-related disasters that occurred in Kanagawa Prefecture in the 85 years between 1934 and 2019. This means that, on average, there is one weather-related disaster per year, which is extremely frequent [25].

\section{Materials and Methods'}

\subsection{Summary of the Data}

In the present study, we focused on four types of disaster: seismic, floods, tsunami, and sediment disaster. Obviously, a hazard is not a disaster if it occurs in 
an uninhabited area. Thus, we also examined parameters associated with population. We used data published online [17] [23] [26] [27]. Designated evacuation Center data lent from the Yokohama City Emergency Management Office. A list of the data is shown in Table 1.

\subsubsection{Seismic Hazard}

For seismic hazard, we chose "Maps of Seismic Intensity That is Expected with a Probability of $3 \%$ within 30 Years" by J-SHIS, where "seismic intensity" is used as the output, as it is the easiest for the general public to understand. Since the data is published with a $250-\mathrm{m}$ mesh, there is no area without hazard. The hazard coefficient discussed later was the seismic intensity. Areas around our target area of Yokohama City do not have clearly confirmed active faults. Thus, the level of seismic hazard is strongly affected by the susceptibility of the ground.

\subsubsection{Flood Hazard}

For flood hazard, we focused on the hazard from overflowing rivers and selected data on the inundation area forecast from the digital national land information. This is polygon data prepared for each depth of inundation based on the data provided by river management. In Kanagawa Prefecture, there are data prepared by The Ministry of Land, Infrastructure, Transport and Tourism and data prepared by Kanagawa Prefecture, where the inundation depth ranking is different. We set the flood hazard coefficient to the higher flood rank, with values of $5.0 \mathrm{~m}$ or higher being considered as $10.0 \mathrm{~m}$. Since flood hazard targets urban floods for which the extent of inundation has been forecast, inundation by mid- to small-sized rivers and river floods were excluded from the present analysis. Inundation by tsunami was considered as a separate tsunami hazard.

\subsubsection{Tsunami Hazard}

We defined tsunami hazard as "inundation from tsunami" and selected tsunami inundation forecast data from the digital national land information. This is polygon data subdivided into expected tsunami inundation depth and maximum inundation depth based on data provided by prefectures. As with flood hazard

Table 1. A list of the original data.

\begin{tabular}{|c|c|c|}
\hline & Data source & Data content \\
\hline Seimic & NIED, J-SHIS [23] [26] & $\begin{array}{l}\text { Maps of Seismic Intensity That is Expected With a } \\
\text { Probability of 3\% Within } 30 \text { Years }\end{array}$ \\
\hline Flood & MLIT [17] & Inundation assumption data based on estimated rainfall \\
\hline Tsunami & MLIT [17] & Inundation assumption data due to assumed tsunami \\
\hline Sediment & MLIT [17] & $\begin{array}{l}\text { Sediment-related disaster warning area designated by } \\
\text { prefectures }\end{array}$ \\
\hline Population & e-STAT [27] & Population the census with town/street as the unit \\
\hline $\begin{array}{l}\text { Designated } \\
\text { evacuation }\end{array}$ & $\begin{array}{l}\text { Yokohama City Emergency } \\
\text { Management Office }[21]^{\star}\end{array}$ & $\begin{array}{l}\text { Designated evacuation centers decided by Yokohama } \\
\text { City }\end{array}$ \\
\hline
\end{tabular}


rank, we chose the tsunami inundation hazard coefficient for the higher inundation rank.

\subsubsection{Sediment Hazard}

We defined Sediment hazard as "slope failure hazard" and selected landslide disaster warming zone data from the digital national land information. This is polygon data of landslide disaster warning zone (yellow zone) and landslide disaster special warning zone (red zone) designated by each prefecture. We set the landslide hazard coefficient with three times more weight on the red zone than yellow zone in consideration of the higher risk. We tried three, five, and ten times more weight to confirm that the difference in weight has little impact on the result.

\subsubsection{Designated Evacuation Center and Population}

In Yokohama City, about 400 designated evacuation centers have been set in the regional disaster prevention plan. Figure 4 shows the location of the designated evacuation center. Designated evacuation centers are set up mainly in elementary schools and are supposed to accommodate about 1000 people. In the event of

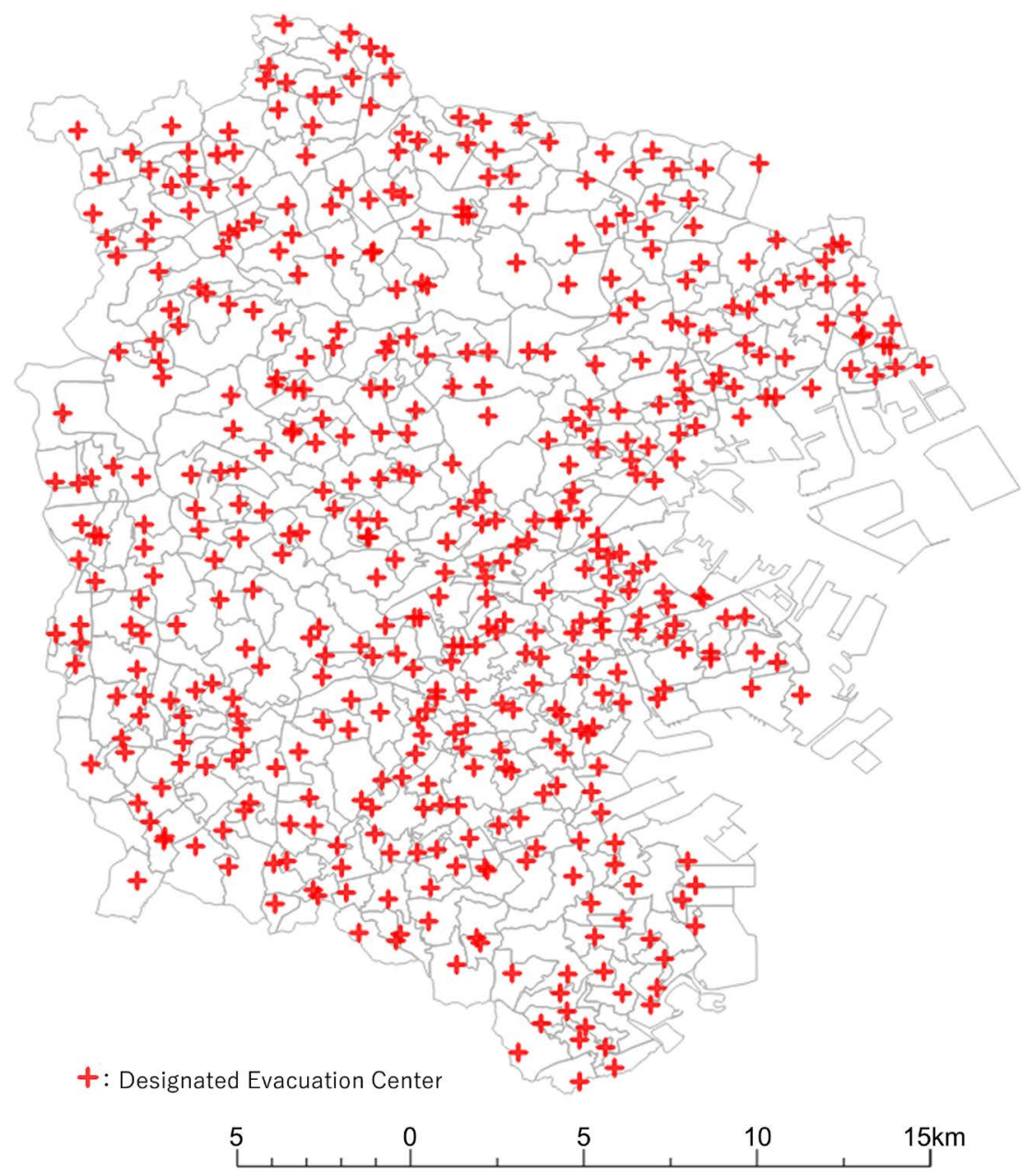

Figure 4. Designated evacuation center and area [21]. 
a disaster, the city will provide various supplies, mainly food and beverages, and disaster information, to designated evacuation centers.

For the target designated evacuation center, we used data from the Yokohama City Emergency Management Office. Designated evacuation center is the area whose residents are expected to evacuate to each designated evacuation center set up in Yokohama City. This data is also polygon data.

We selected the population data from e-stat. This is polygon data from the census with town/street as the unit. As for the population, the higher the density, the higher the risk to disasters, so the population density was used as the coefficient of the data.

\subsection{Assessment Method for Each Hazard}

As shown in Section 3, the hazard data used is open data that can be accessed online. The seismic intensity distribution used for seismic hazard is mesh data, and all other hazards are provided as polygon data.

Evacuation center area is [A]. And first, use GIS [Geographic Information Systems] to find area where the hazard and evacuation center polygons overlap [Bi]. Finally, use the formula [1] and the hazard coefficient to calculate the evacuation center hazard.

$$
H=\left\{\left(\frac{B_{i} \times h_{i}}{A}\right)+\left(\frac{B_{i+1} \times h_{i+2}}{A}\right)+\cdots\right\}
$$

$H$ : Hazard for a designated evacuation center

$A$ : Area of each designated evacuation center $\left(\mathrm{m}^{2}\right)$

$B_{i}$ : Area of hazard within designated evacuation center $\left(\mathrm{m}^{2}\right)$

$h_{i}$ : Hazard coefficient

In addition, since the hazard distribution map is intended for relative comparison of each hazard, it was standardized [Average is 0 , Standard deviation is 1] and divided into 5 stages according to the natural classification (Fisher-Jenks).

1) Seismic hazard

The seismic hazard and the original data are shown in Figure 5. Seismic hazard shows that there are areas with high seismic intensities along the coast and rivers. This is because the size of seismic intensity is associated with the susceptibility of the ground to shaking. In other words, areas with softer ground are areas with high seismic hazard.

2) Flood hazard

The flood hazard and the original data are shown in Figure 6. Flood hazard is high in lowlands along rivers. Flood hazard is especially high for the Tsurumi River Basin in the north. In contrast, hazard is zero in the southeastern area where there are no large rivers.

3) Tsunami hazard

The tsunami hazard and the original data are shown in Figure 7. Tsunami hazard is high in the coastal areas. Within the coastal areas, areas of lower elevations have higher hazard. In contrast, as with flood hazard, since inundation by tsunami is not expected in the inland area, hazard would be zero in this area. 
Hazard for a designated evacuation center

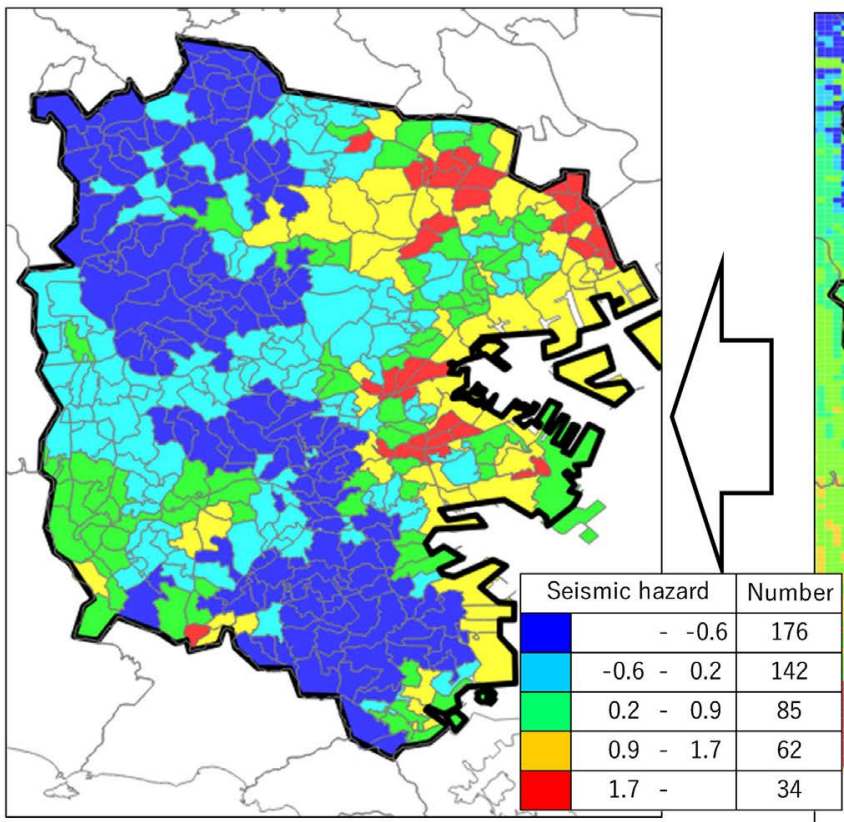

Original data

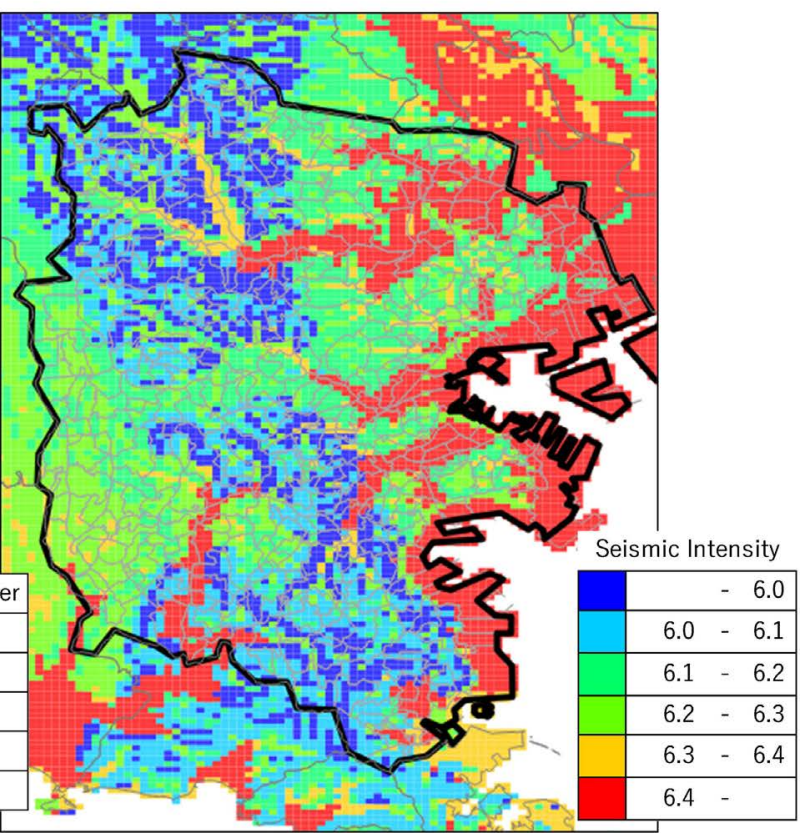

5 $15 \mathrm{~km}$

Figure 5. Seismic hazard and original data.

Hazard for a designated evacuation center Original data
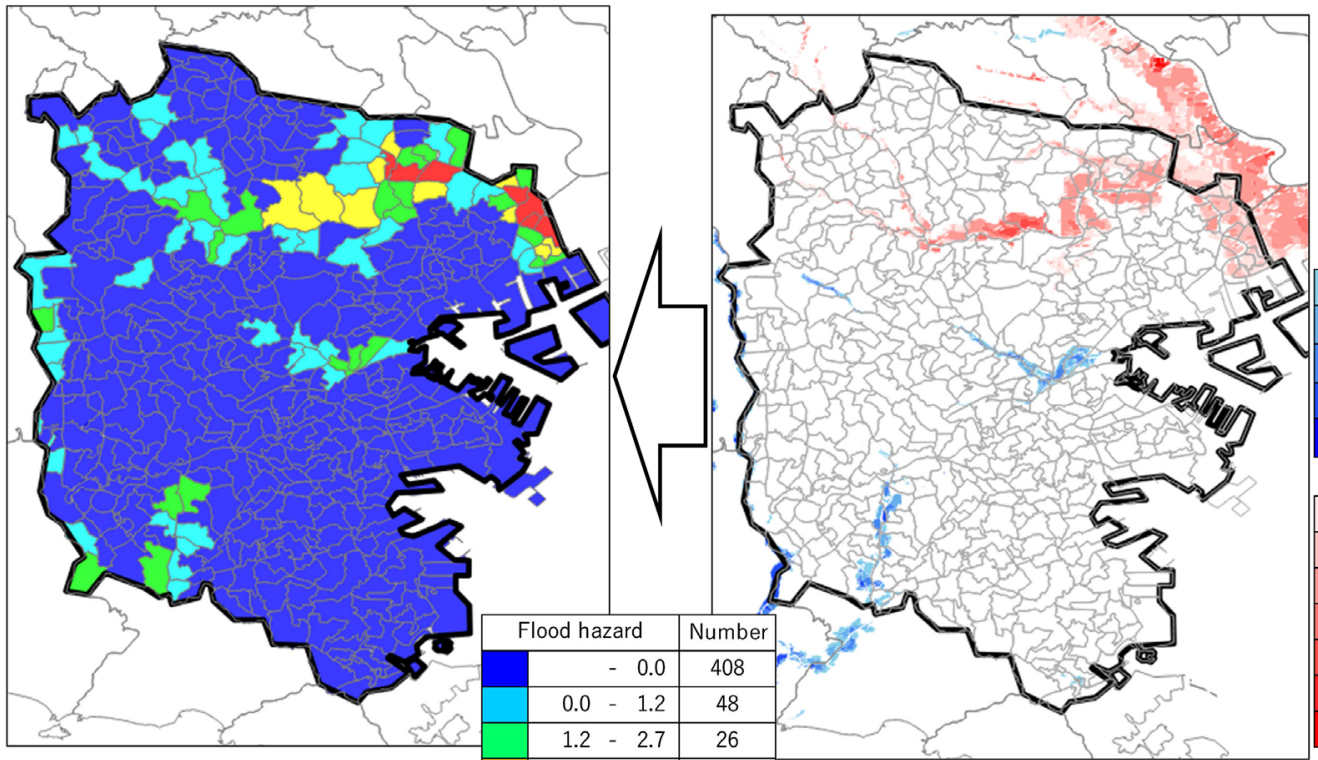

Depth of Inundation from Pref.
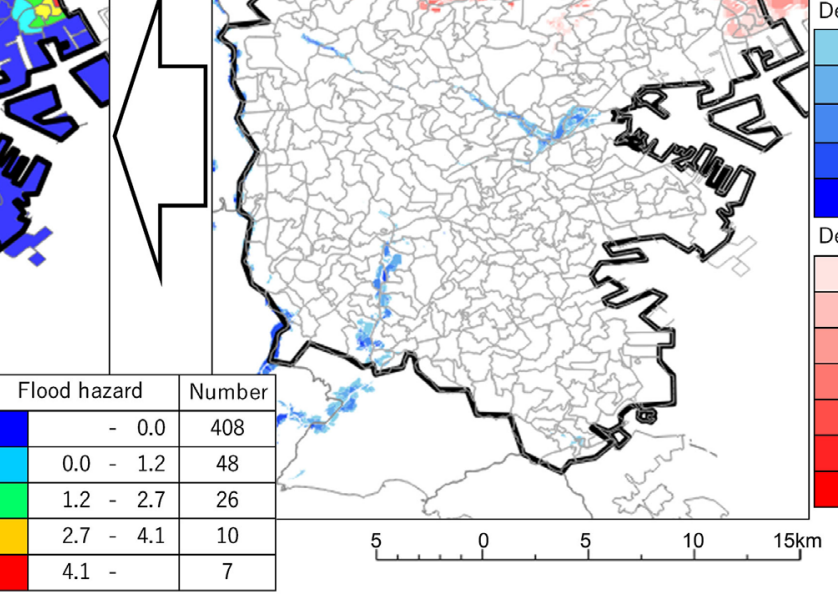

Figure 6. Flood hazard and original data.

4) Sediment hazard

The sediment hazard and the original data are shown in Figure 8. Sediment disaster hazard is high from the central area to the southeast. As discussed in Section 2, the southeastern area is hilly with steep slopes, which increases Sediment hazard. 


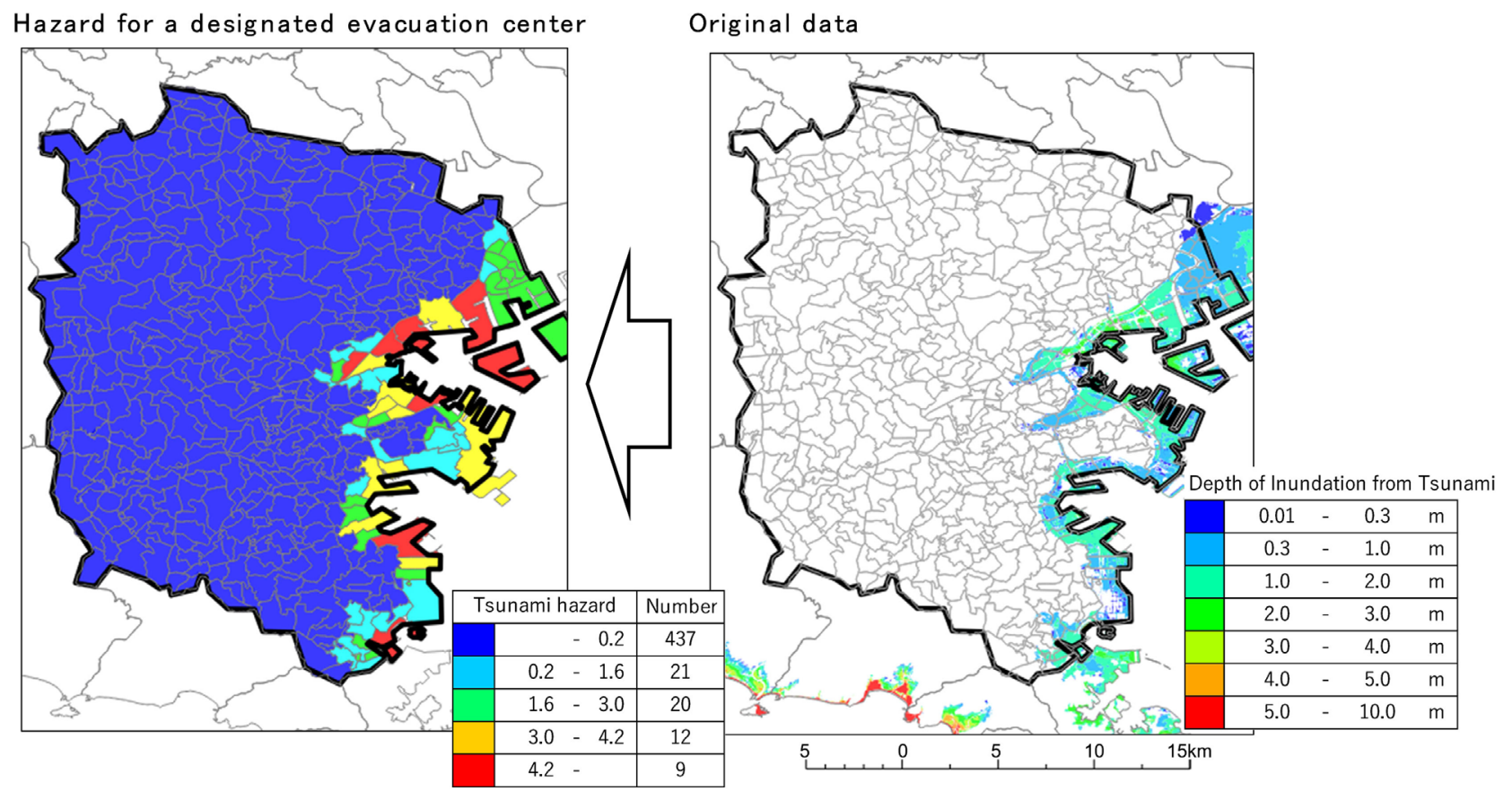

Figure 7. Tsunami hazard and original data.

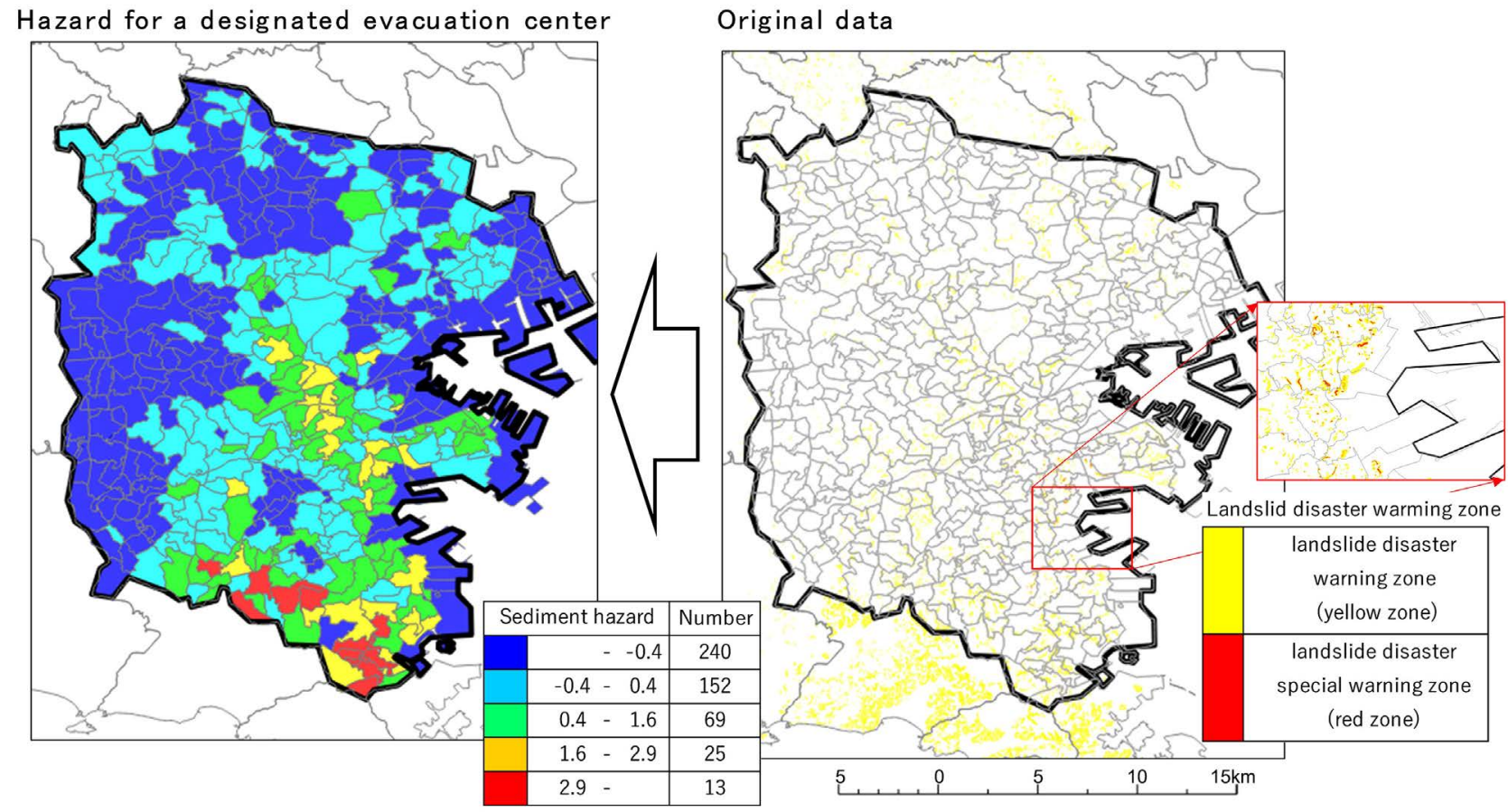

Figure 8. Sediment hazard and original data.

\section{5) Population}

The population and the original data are shown in Figure 9. Population density is low in the coastal areas and in the west. Coastal areas are landfills with many industrial zones, which reduces the number of residents. Elsewhere, in the west, there is a relatively large area of farmland within Yokohama City which 


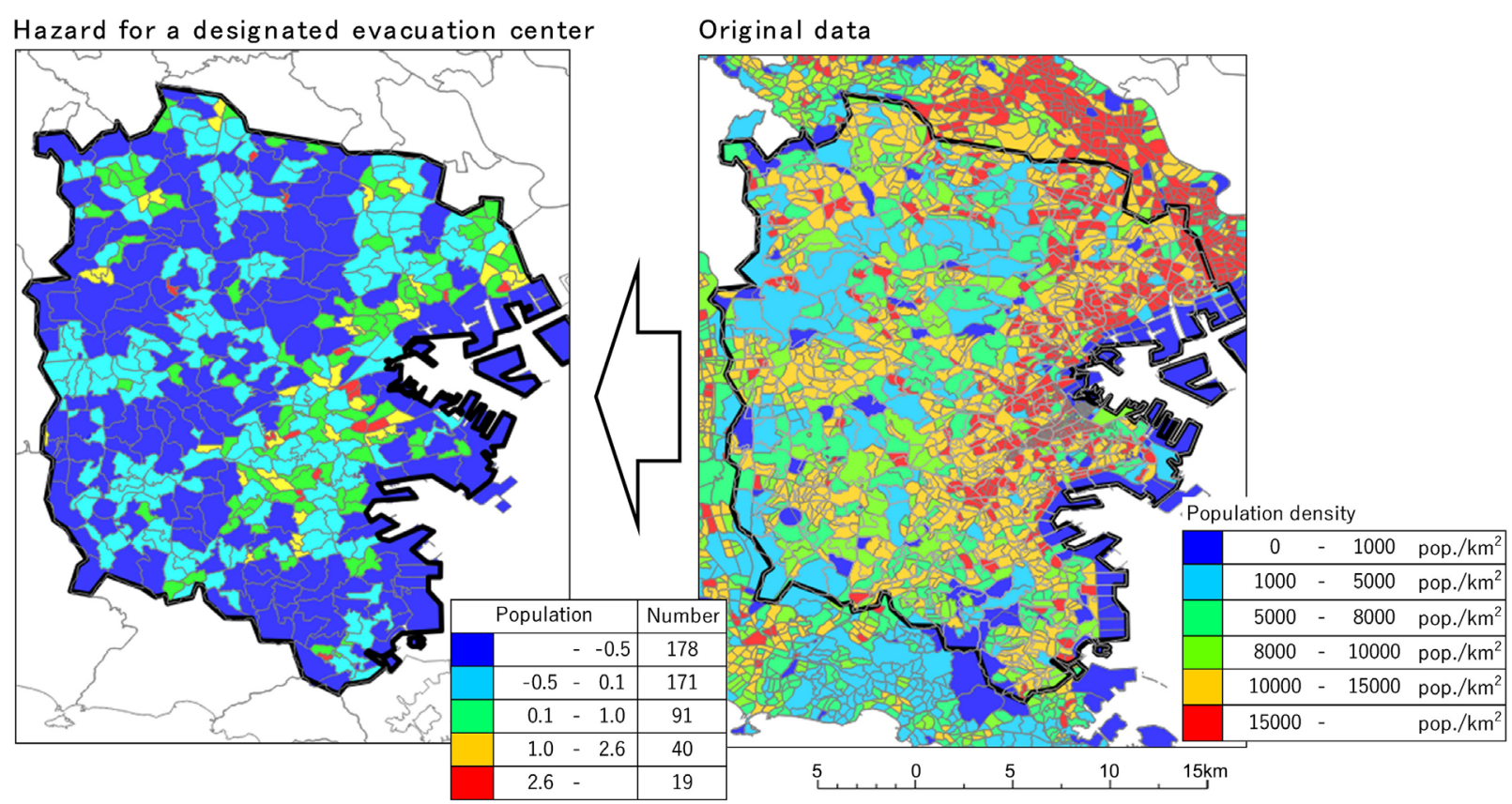

Figure 9. Population and original data.

reduces the population relative to the central area. The area with the highest population density (red) is near Kannai Station around the old town.

\subsection{Cluster Analysis}

Since we combined multiple hazards for assessment, we performed a cluster analysis with four hazards and population data as parameters. Cluster analysis combines individuals with similar data patterns into the same group. Here, we used the Euclidean distance as the scale of similarity and Word clustering as the grouping method [28].

In cluster analysis, it is important to set the number of groups to classify. It is important that the data are not similar if the groups are different, and that the data are similar if the groups are the same. In previous studies often used, for example, ANOVA and silhouette [29] [30] [31].

On the other hand, I think 4 - 7 groups are appropriate for recognizing the features grouped on the map. Therefore, we divided them into 4 to 7 groups and checked them on the map and decided on the number of groups that we judged to be the most appropriate.

\section{Results and Discussions}

\subsection{Results of Cluster Analysis}

First, I changed the number of groups and tried cluster analysis several times. Referring to a dendrogram (Figure 10) and map (Figure 11), we used 6 Groups for the cluster. Figure 11 shows evacuation center divided into 6 groups, and Figure 12 shows the scatter plot matrix of each hazard. The characteristics of each hazard group are shown below: 


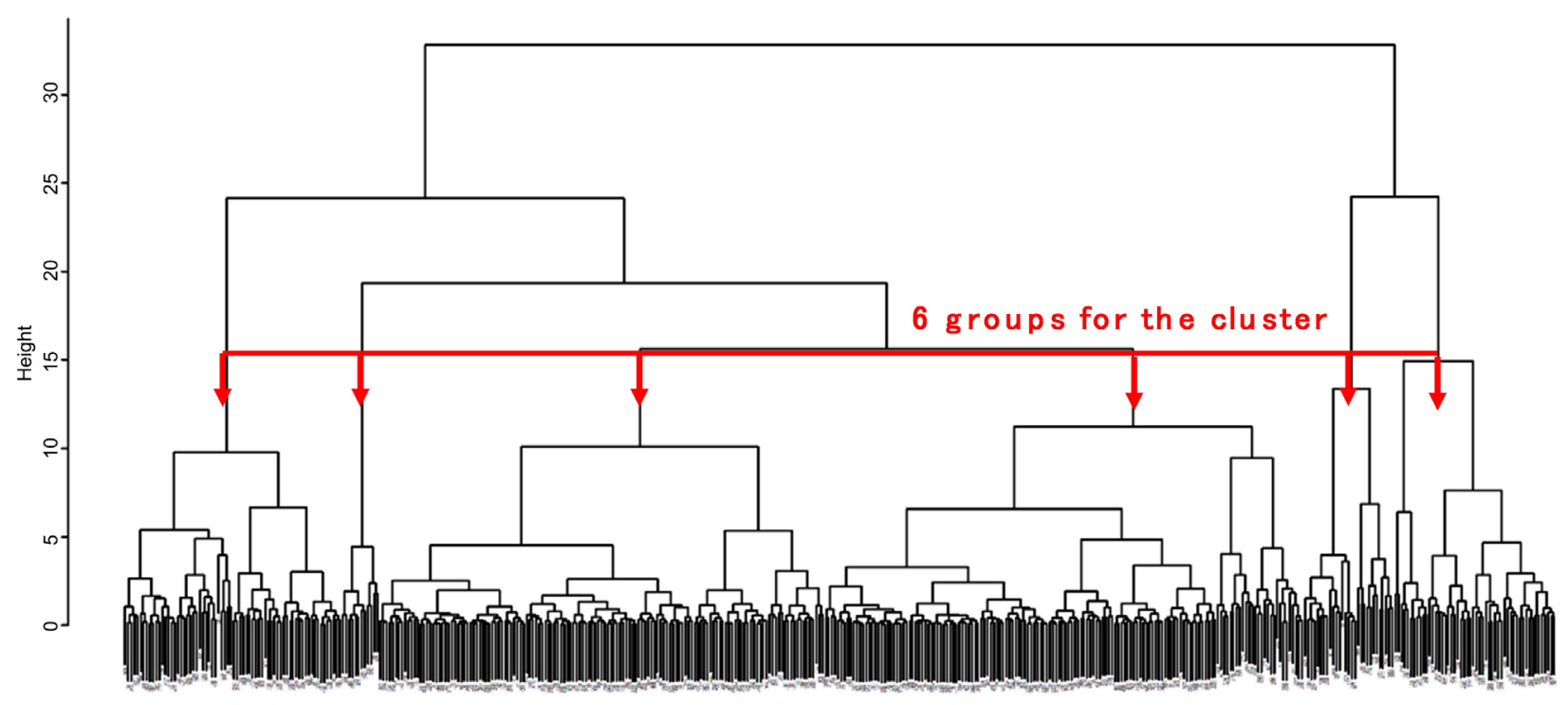

Figure 10. Dendrogram from ward method.

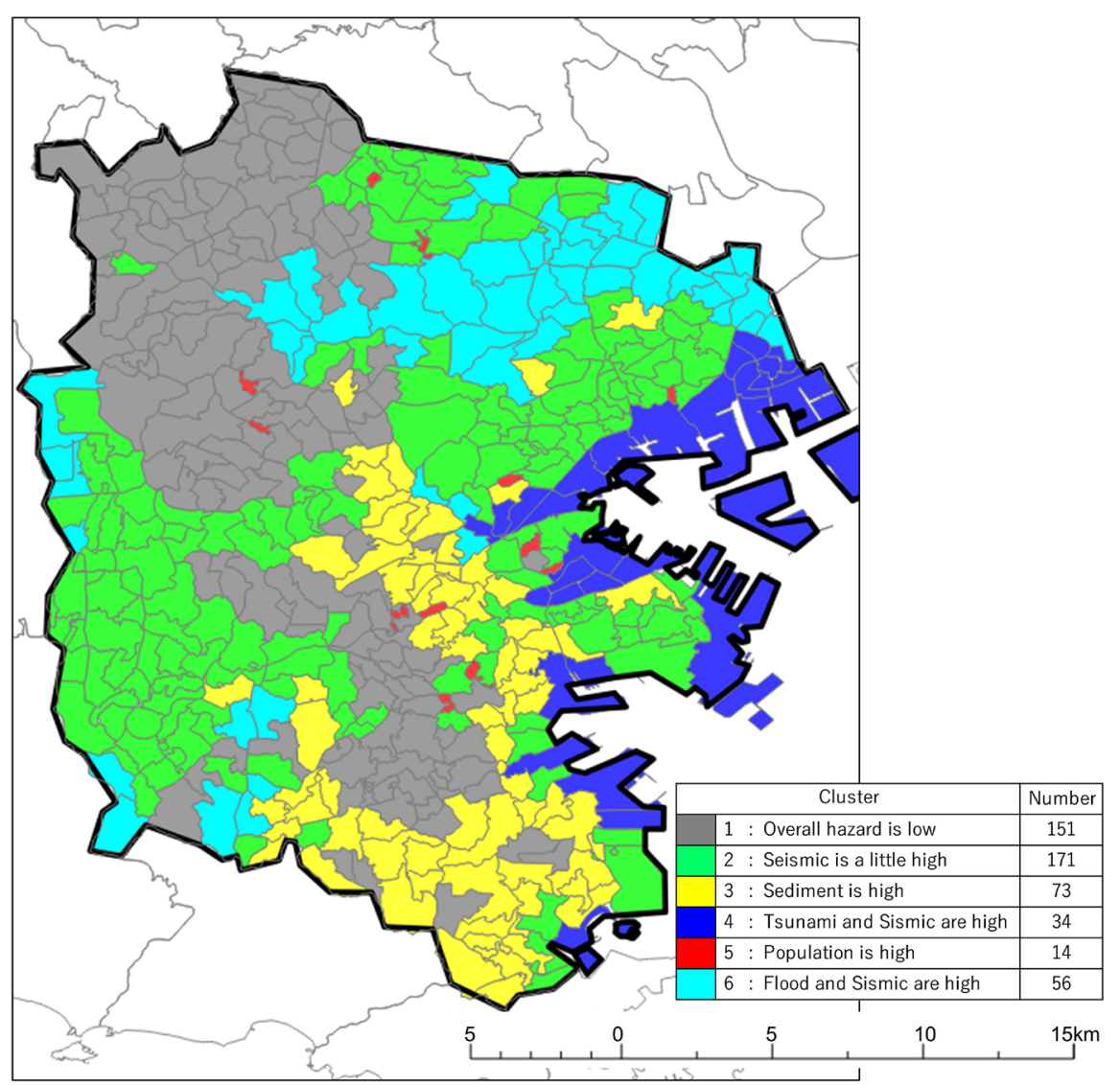

Figure 11. Evacuation center cluster analysis result.

- Group 1: Overall hazard is low.

It is distributed inland in the northwest and south.

- Group 2: Seismic hazards are a little high, and tsunamis and sediment hazards are also a little high in some areas. 


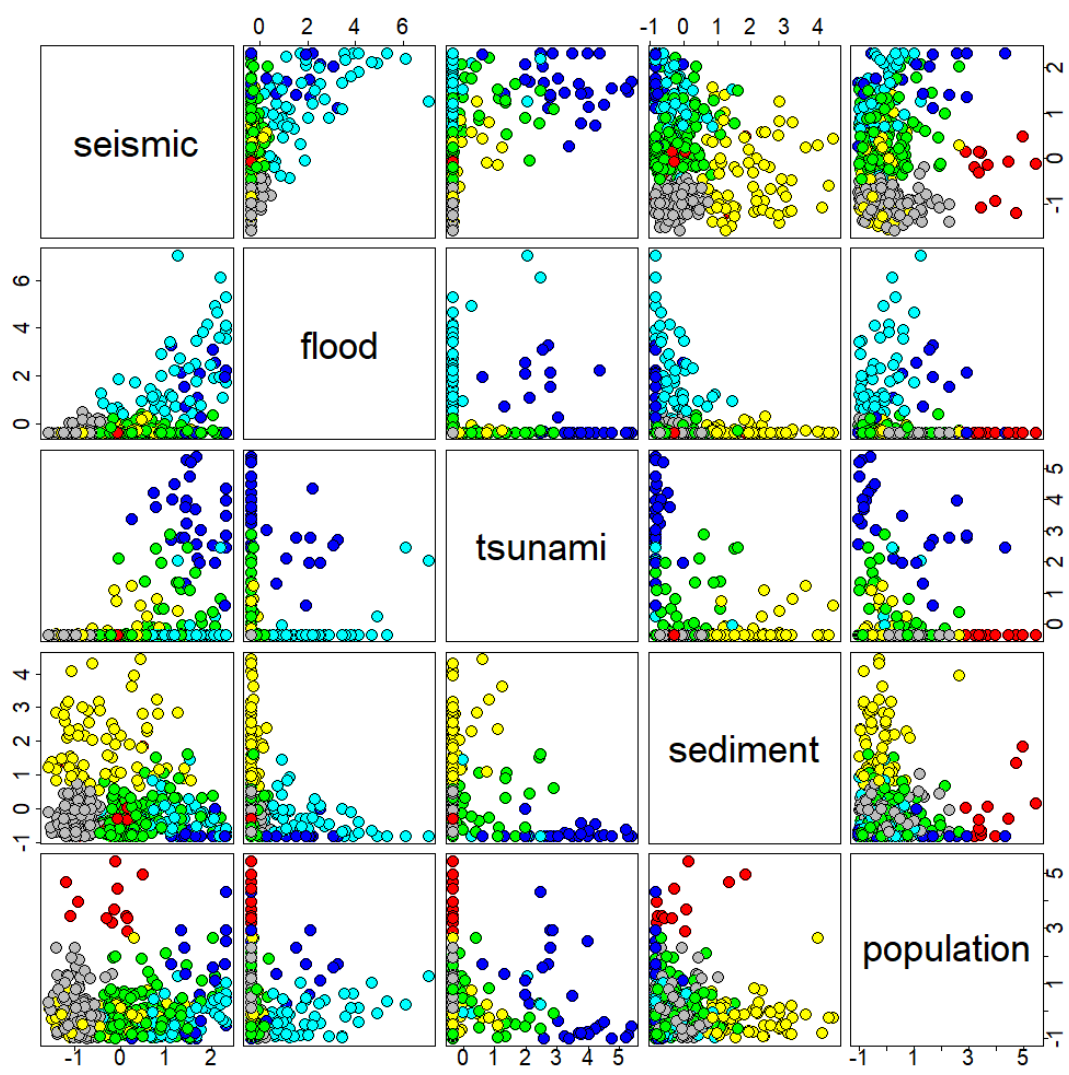

Figure 12. Plot matrix of each hazard.

There are not many regional characteristics, but it is distributed in areas slightly outside rivers and coastal areas.

Group 3: Sediment hazards are particularly high, and seismic hazards are also somewhat high in some areas.

It is mainly distributed in the hills in the southeastern part.

- Group 4: Tsunami and seismic hazards are particularly high, and some other flood hazards are also slightly high.

It is distributed near the coastal lowlands and estuaries of rivers.

- Group 5: Areas with a particularly high population density.

The area is low, and the area is narrow.

- Group 6: Flood and seismic hazards are particularly high, other hazards are low.

It is distributed along rivers (especially along the Tsurumi River in the north).

${ }^{*}$ From group $6(\bigcirc)$ of the scatter plot matrix, a positive correlation can be confirmed between the seismic hazard and the flood hazard (the higher the seismic hazard, the higher the flood hazard).

\subsection{Comparison with Ground Hazard Actual Measurements}

Figure 13 shows the distribution of ground hazard assessment in Yokohama City according to a separate study conducted by the authors [12] [13]. Details of ground hazard are described in the paper [12], of which we present a summary here. 


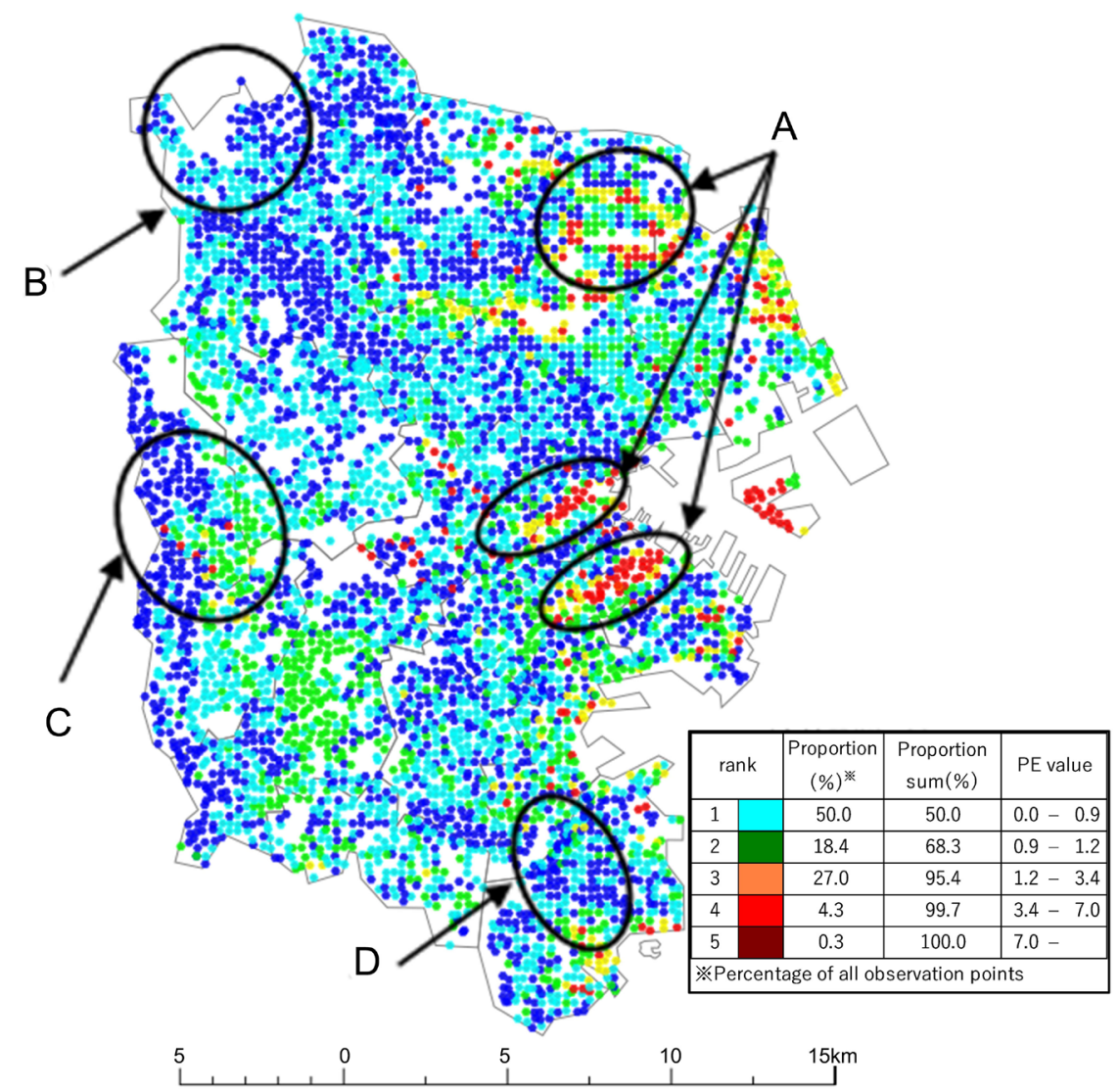

Figure 13. Ground hazard actual measurements [19].

We used an interval of approximately $250 \mathrm{~m}$ to constantly observe microtremors in the target area. The ground $\mathrm{H} / \mathrm{V}$ spectral ratio was obtained from the results. From the H/V spectral ratio, the predominant period of ground and the peak value-its vertical axis-were identified. By multiplying both, we obtained the ground hazard. In areas with complex ground, $250 \mathrm{~m}$ may not be sufficient. However, when evaluating a wide area with a unified standard for the purpose of disaster prevention, it can be said that the limit is about $250 \mathrm{~m}$.

First, we compared the ground hazard assessment based on actual measurements to the distribution of seismic hazard. Trends were consistent for the following points: high hazard in coastal areas and along rivers, and hazard decreasing from the central area toward the northwest and southeast.

Next, we compared the results of the cluster analysis for the combined hazards to the ground hazard assessment based on actual measurements. Although there are some differences compared to the hazards of the seismic, clusters 2, 4 and 6 with large seismic hazards have large hazards even in actual measurement. Conversely, the inland central area of Group 1 with low overall hazard value had low measured ground hazard as well.

\section{Conclusions}

The present study summarized and assessed hazard data that can be accessed 
online regarding designated shelter catchments in Yokohama City, Kanagawa Prefecture. Based on the result, we performed a multi-hazard assessment through grouping via cluster analysis. From each result, the effectiveness of multi-hazard evaluation using cluster analysis was confirmed. The individual results are summarized below:

First, in addition to the four hazards data of seismic, floods, tsunamis, and landslides, we created data that can organize and analyze the population in the same way. Second, for each hazard, we identified catchments where typical hazard values are high. Third, based on five parameters (the 4 hazards plus population), we divided designated evacuation center into 6 groups through cluster analysis. Forth, the 6 groups created by the cluster analysis had unique characteristics that could be explained, confirming the effectiveness of multi-hazard maps using cluster analysis. Fifth, in particular, Group 6 was found to have a positive correlation between seismic hazards and flood hazards. This is consistent with the general tendency for low-altitude soft ground along rivers to have high seismic hazards and high flood hazards.

In the future, we plan to investigate whether similar trends can be observed in studies targeting different and wider areas. In addition, setting the number of groups by cluster analysis is also an issue for future study.

\section{Acknowledgements}

The polygon data of designated evacuation center analyzed in the present study were provided by the Yokohama City Emergency Management Office. For data organization and analysis, we received support from Mr. Kaito Hiratsuka, an affiliate of the laboratory. We would like to express our most sincere appreciation.

\section{Conflicts of Interest}

The authors declare no conflicts of interest regarding the publication of this paper.

\section{References}

[1] Nakabayashi, I. and Otagiri, R. (2009) The Present and Issue on Governmental Measures against Compound Disasters and Mega Disasters in Japan. Journal of Social Safety Science, 11, 33-42.

[2] Tohno, I. (1993) A Study on the Natural Disasters Caused by Multiple Origins -Their Influences and the Comprehensive Hazard Map. The Quaternary Research, 32, 339-352. https://doi.org/10.4116/jaqua.32.339

[3] Ministry of Land, Infrastructure, Transport and Tourism (2021) Hazard Map Portal Site. https://disaportal.gsi.go.jp/index.html

[4] Takada, K., Fujiu, M. and Konno, T. (2016) Consciousness Analysis of Evacuation from Compound Disaster. Journal of Japan Association for Earthquake Engineering, 16, 12-26. https://doi.org/10.5610/jaee.16.2_12

[5] Takada, K., Fujiu, M., Ohara, M., Yamashita, T. and Konno, T. (2016) Estimation of Disaster Evacuation Behavior Model using Stated Preference Data. Journal of Japan 
Association for Earthquake Engineering, 16, 46-55.

https://doi.org/10.5610/jaee.16.5_46

[6] Itagaki, O., Matsuura, T. and Hattori, A. (2016) Case Study on Characteristics of Effect of Damage Reduction Measures against Multiple Disasters of Earthquakes and Floods. Journal of Japan Association for Earthquake Engineering, 16, 26-40. https://doi.org/10.5610/jaee.16.11_26

[7] Kawasaki, K., Kim, M., Shimokawa, S. and Murakami, T. (2016) Storm Surge Inundation Prediction in Osaka Port due to Complex Coastal Disaster of Huge Earthquake and Typhoon. Journal of Japan Society of Civil Engineers, B3, 72, I_13-I_18. https://doi.org/10.2208/jscejoe.72.I_13

[8] Tamura, K., Nagata, S., Takahara, H. and Wakabayashi, R. (2007) Proposal of Practical Risk Assessment Method of Multiple Natural Hazards. Japan Society of Civil Engineers Journal of Earthquake Engineering, 29, 88-97.

[9] Flax, L.K., Jackson, R.W. and Stein, D.N. (2002) Community Vulnerability Assessment Tool Methodology, Natural Hazards Review, 3, 163-176. https://doi.org/10.1061/(ASCE)1527-6988(2002)3:4(163)

[10] Federal Emergency Management Agency (n.d.) Multihazard Information Platform. https://hazards.fema.gov/femaportal/resources/outreach/mip_onepager.htm

[11] Peng, S.-H., Shieh, M.-J. and Fan, S.-Y. (2012) Potential Hazard Map for Disaster Prevention Using GIS-Based Linear Combination Approach and Analytic Hierarchy Method. Journal of Geographic Information System, 4, 403-411. https://doi.org/10.4236/jgis.2012.45046

[12] Guettouche, A. (2019) Using a GIS to Assess the Land Movements Hazard: Application on Berhoum Area, Hodna Basin, Algeria. Journal of Geographic Information System, 11, 166-184. https://doi.org/10.4236/jgis.2019.112012

[13] Sangeeta, A. (2012) Regionalization of River Basins Using Cluster Ensemble. Journal of Water Resource and Protection, 4, 560-566. https://doi.org/10.4236/jwarp.2012.47065

[14] Ley, R., Casper, M.M., Hellebrand, H. and Merz, R. (2011) Catchment Classification by Runoff Behaviour with Self-Organizing Maps (SOM). Hydrology and Earth System Sciences, 15, 2947-2962. https://doi.org/10.5194/hess-15-2947-2011

[15] Enomura, Y. (2012) Study on Measures to Enhance Residents' Recognition and Understanding of Flood Hazard Map. Journal of Japan Society of Civil Engineers D, 68, I_103-I_110. https://doi.org/10.2208/jscejipm.68.I_103

[16] Katada, T., Kimura, S. and Kodama, M. (2007) Desirable Utilization of Flood Hazard Maps for Risk Communication. Journal of Japan Society of Civil Engineers D, 63, 498-508. https://doi.org/10.2208/jscejd.63.498

[17] Ministry of Land, Infrastructure, Transport and Tourism (2021) National Land Numerical Information Download Site. https://nlftp.mlit.go.jp/ksj/index.html

[18] Urata, M., Ogishima, K., Chujo, H., Endo, M. and Yasuda T. (2018) Promotion of Local Government Open Data on Disaster Prevention Information. Journal of Socio-Informatics, 7, 1-17.

[19] Ochiai, T., Inubushi, T. and Enomoto, T. (2020) Creation of Hazard Maps by Considering Regional Characteristics by Microtremor. Journal of Japan Association for Earthquake Engineering, 20, 19-31.

[20] Ochiai, T. and Enomoto, T. (2019) Analysis on Predominant Periods Distribution by Microtremor Observations for Seismic Disaster Prevention in Yokohama, Japan Using GIS, Journal of Geographic Information System, 11, 579-594. 
https://doi.org/10.4236/jgis.2019.115036

[21] Yokohama City (2021) Yokohama City Homepage. https://www.city.yokohama.lg.jp/lang/residents/en/

[22] Kanto Branch of Japanese Geotechnical Society (2010) Ooinal Kanagawa no Jiban. Gihodobooks, Tokyo.

[23] National Research Institute for Earth Science and Disaster Resilience (n.d.) j-SHIS Japan Seismic Hazard Information Station. https://www.j-shis.bosai.go.jp/

[24] Geospatial Information Authority of Japan (1997) Numerical Map 50m Mesh (Elevation).

[25] Yokohama Local Meteorological Office, Japan Meteorological Agency (2021). https://www.jma-net.go.jp/yokohama/index.html

[26] Wakamatsu, K. and Matsuoka, M. (2013) Nationwide 7.5-Arc-Second Japan Engineering Geomorphologic Classification Map and Vs30 Zoning. Journal of Disaster Research, 8, 904-911. https://doi.org/10.20965/jdr.2013.p0904

[27] e-Stat (2021) Portal Site of Official Statistics of Japan. https://www.e-stat.go.jp/

[28] R Core Team (2020) R Version 3.6 .3 (2020-02-29) - “Holding the Windsock" Copyright (C) 2020 The $\mathrm{R}$ Foundation for Statistical Computing, Platform: x86_64-w64-mingw32/x64 (64-bit)

[29] Rousseeuw, P.J. (1987) Silhouettes: A Graphical Aid to the Interpretation and Validation of Cluster Analysis. Journal of Computational and Applied Mathematics, 20, 53-65. https://doi.org/10.1016/0377-0427(87)90125-7

[30] Kaufman, L. and Rousseeuw, P.J. (1990) Finding Groups in Data: An Introduction to Cluster analysis. John Wiley \& Sons, Inc., Hoboken.

[31] Malika, C., Ghazzali, N., Boiteau, V. and Niknafs, A. (2014) NbClust: An R Package for Determining the Relevant Number of Clusters in a Data Set. Journal of Statistical Software, 61, 1-36. https://doi.org/10.18637/jss.v061.i06 